Helgoländer wiss. Meeresunters. 24, 82-90 (1973)

\title{
Evaluation of lock-out submarine "Deep Diver" for in situ biological work in boreal waters
}

\author{
R. A. CoOper $^{1} \&$ D. J. SCARratt ${ }^{2}$ \\ ${ }^{1}$ National Marine Fisheries Service; Boothbay Harbor, Maine, USA \\ and \\ 2 Fisheries Research Board of Canada; St. Andrews, N.B., Canada
}

\begin{abstract}
EXTRAIT: Valeur du sousmarin à plongée humide "Deep Diver» pour les recherches in situ dans les eaux boréales. Dans le cadre d'un programme à long terme, subventionné par le "Manned Undersea Science and Technology Office" (MUS\&T) de la NOAA en vue de développer les possibilités de travail sousmarin, six savants et techniciens de la biologie marine furent entrânnés, à partir du submersible «Deep Diver», à des plongées humides utilisant des mélanges respiratoires d'air, hélium et oxygène. Un programme de plongée saturée à 45-76 mètres, utilisant comme habitacle des plongeurs une chambre de décompression maintenue à une pression correspondant à 45 mètres de hauteur d'eau, n'eut qu'un succès partiel, en raison du froid pénible auquel furent somis les plongeurs dans une eau à $3,5^{\circ} \mathrm{C}$ et de défectuosités apparues dans l'équipement sousmarin. Un programme alternatif utilisa la plongée rapide, humide et non saturée, la décompression commençant dans le sousmarin et s'achevant dans la dhambre de décompression; il permit d'accomplir à peu près tout le programme scientifique prévu. Au cours de 18 plongées fut atteinte la profondeur maximum de 87,5 mètres. Les plongeurs prirent des photographies, récoltèrent des échantillons de roches et de sédiments en vue d'analyser les contaminations par des agents polluants. Il fut démontré qu'un submersible, couplé avec la chambre de décompression adaptée, constitue un équipement susceptible d'aboutir à des observations in situ du fond sousmarin et que des plongeurs de tormation scientifique peuvent être rapidement entraînés à effecteur sans danger des plongées humides et à utiliser des techniques de plongée hautement spécialisées.
\end{abstract}

\section{INTRODUCTION}

The use of diving as a tool in marine biological and fisheries science is now too well known to require documentation. So too are depth and time limits within which surface-oriented divers must work. A number of well-known habitat programs have effectively resolved the time constraint, at least for shallow water, and have allowed long-term experiments and observations to be carried out by a large number of marine scientists.

There are a number of areas where, by reasons of climate or the nature of the program, placement of a habitat is not an appropriate method of putting divers on the sea bed. Either the study area is too large, too exposed, the weather too unreliable, or the program requires mobility. The solution is to bring the habitat aboard ship allowing 
for continual pressurization (storage) of the dive team with periodic transport to the work site by diving bell, or submarine. This gives a high degree of surface control and safety. It does not permit instantaneous sorties by any diver at any time, and if storage and sortie depth are different, there may be restrictions on dive time. It does offer a wider range for exploration than is available to a diver restricted to the immediate vicinity of a habitat, by reason of the mobility of the surface support ship.

To our knowledge this is the first attempt at using a submersible with mating deck decompression chamber (DDC) for a saturation diving program for scientific purposes. This paper describes the equipment and methods used in the program, and the modifications that proved necessary in the light of experience.

\section{ORGANIZATION}

This program was the first major field operation of the New England Man-InThe-Sea-Program (NEMITS) of the National Marine Fisheries Service (NMFS) Northeast Fisheries Research Center based at Boothbay Harbor, Maine (USA). Primary financial support of this program is from the Manned Undersea Science and Technology Office, National Oceanic and Atmospheric Administration (NOAA), Rockville, Maryland.

Guest scientists from the Fisheries Research Board of Canada (3 diver/scientists), the Environmental Protection Agency, Kingston, Rhode Island (4 surface support scientists), and the Maine Department of Sea and Shore Fisheries (1 surface support scientist) were major participants in this 3-week program. NEMITS personnel totaled 8: 4 diver/scientists, 2 surface support and 2 boat skippers. Perry Oceanographics, Inc., Riviera Beach, Florida, the prime contractor, supplied a total of 11 people ranging from project supervisor to medical diving officer, submarine pilot, diving officer, vessel skipper, cook and line handlers. A total of 27 persons were involved full time or part time in the execution of this program.

\section{EQUIPMENT}

The submersible used was the two compartment, Perry-Link "Deep Diver", the first to be designed specifically for lock-out work. Pilot and observer occupy the forward compartment, and the after compartment has space for 2 divers. "Deep Diver" was carried in a special frame on the stern of the $38 \mathrm{~m}$ oil-rig service boat "State Wave" and launched and retrieved by a stern mounted A-frame gantry and winch (Fig. 1).

A double lock decompression chamber with a transfer tunnel bolted to the after end was mounted on deck rails and could be winched af so that the transfer tunnel aligned with and could be bolted to the entrance trunk of the submersible. This allowed transfer of divers under pressure. A pressure hatch between chamber and tunnel allowed independent use of the submarine when the chamber was occupied. The main chamber lock was $1.5 \mathrm{~m}$ i.d. $\times 2.5 \mathrm{~m}$ long. 
All piping, valves and gauges were outside the chamber putting control entirely in the hands of the on-deck operators. Gas supply consisted of L.P. compressed air from a deck mounted compressor, giving 56601 at $13.6 \mathrm{~atm}$, and helium, oxygen, and helium/ oxygen mixture from storage tanks, all independently controlled. Oxygen and L.P. air could be supplied to breathing masks inside the chamber. The masks were fitted with

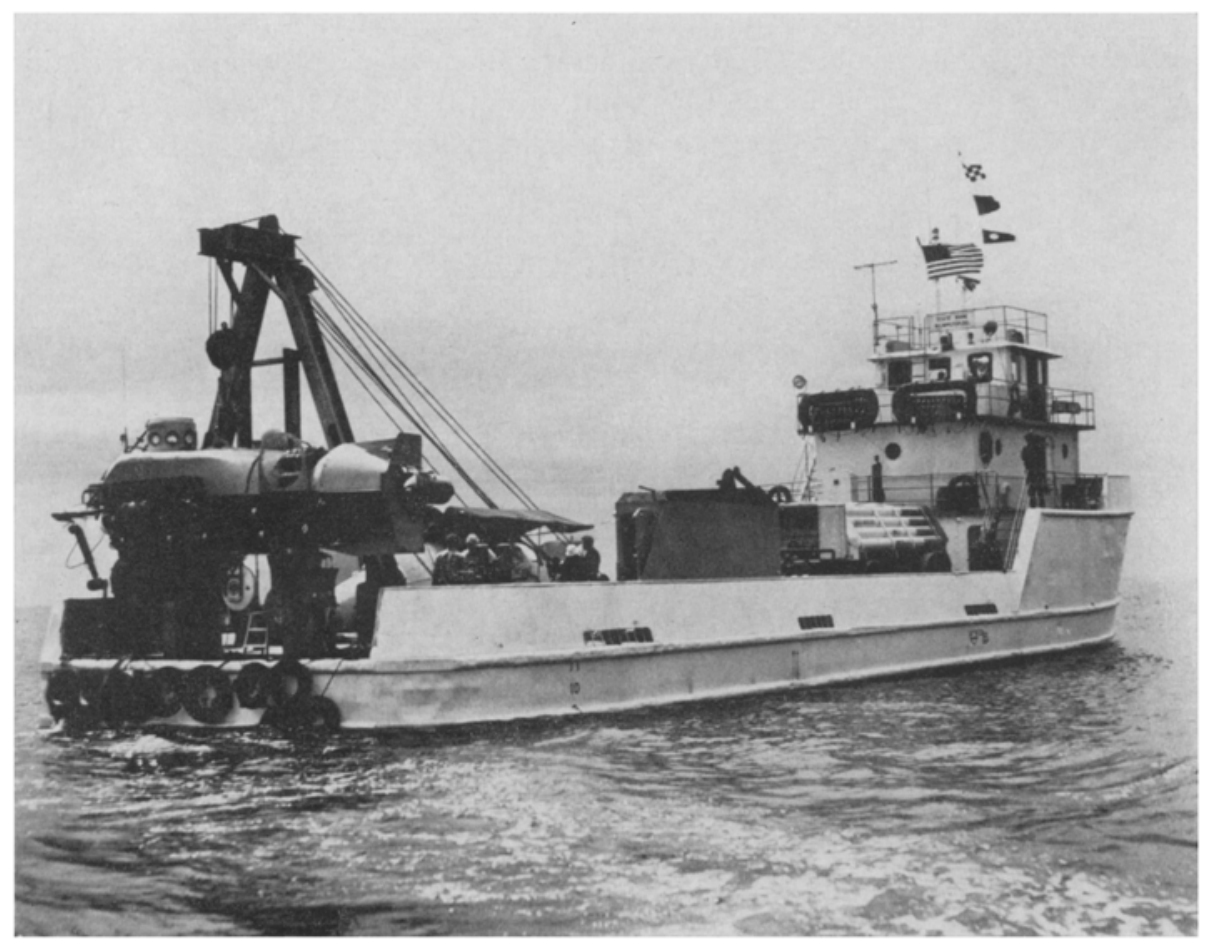

Fig. 1: Motor vessel "State Wave" with diver lock-out submersible "Deep Diver" on stern

outboard exhausts to prevent contamination of chamber atmosphere. Other fittings inside the chamber included a hot-water heater with water-turbine driven fan, $\mathrm{CO}_{2}$ scrubber with sealed 24 v.d.c. motor and magnetic fan drive, a fire hose, a Beckman $\mathrm{O}_{2}$ analyzer and a thermometer. Floor and walls to half height were lined with noncombustible woven synthetic fibre mattresses and the outside was fully insulated with about $3 \mathrm{~cm}$ of neoprene foam. Food, clothing and a portable toilet were locked in and out as required.

A smaller decompression chamber $(1.2 \times 2.4 \mathrm{~m})$ was also mounted on deck and was available for diving emergencies if the main chamber was in use.

Support vessels $(6.4$ and $11.6 \mathrm{~m})$ for standby diver, attendant and radio operator were provided by NMFS.

Divers' equipment, suits, regulators, helmets, etc., were provided by the scientific party. For lock-out dives, Aquasport Poseidon Unisuits were used with nylon fur pile 
underwear, augmented on deep dives by one or more suits of thermal underwear. Initially, all divers used Kirby Morgan Band masks (model 8) with Helle hard wire communications to the submarine. Later these were abandoned in favor of conventional single hose regulators and face masks. Divers' breathing gas was supplied by umbilical hoses from storage bottles on the submarine. Hoses, when not in use, were coiled on racks inside the divers' compartment. Weight belts and shoulder harnesses carried twin 2801 bottles of breathing gas fitted with a single hose regulator for emergency use. Divers also wore conventional fins, knives, gloves and ancillary equipment.

The standby diver wore a Unisuit and for deep dives, a KMB-8 mask supplied via umbilical hose with breathing gas from cylinders on deck, and with hard wire communication to the surface. In shallow water the standby diver used conventional aqualung.

Underwater photography was by Nikonos camera with close-up lens and electronic flash. On deep dives the camera was carried open in the divers' compartment and assembled after pressurization to prevent distortion, flooding, or malfunction. Sampling was done by hand, or with stainless steel scrapers and forceps into plastic bottles, or canvas bags. Collecting nets and other equipment, sediment core tubes, and underwater hand lamps were carried in a rack bolted to the port side of the submarine.

\section{GENERAI PROCEDURES}

\section{Training program}

Six divers in three teams of two were selected for training. Team 1 was comprised of Dr. R. A. Cooper (team leader) and Mr. C. D. Newell, team 2 was Dr. D. J. Scarratt (team leader) and Mr. R. A. Clifford and team 3, Mr. K. J. Peccr (team leader) and Mr. A. A. Wilson. Two had made a lock-out dive from a submersible before (COOPER and SCARRATT), and four had had experience in saturation diving (Cooper, Clifford, Newell and Pecci).

All six divers were thoroughly instructed in lodk-out routines by the professional submarine crew and, in addition to the support personnel, were trained in operation of the deck decompression chambers, compressors, and ancillary equipment.

Each team made two lock-out training dives in depths of $20 \mathrm{~m}$ or less which gave adequate time for thorough learning without incurring decompression penalties. Two teams were scheduled to make the deeper dives, the third team was a backup should any of the principal divers be unable to continue. Standby divers were selected on rotation from the teams not scheduled to ride the submarine.

There were two significant incidents during training. Team 1 allowed a pencil to foul the seal of the inner hatch on completion of the dive. This caused air loss and a premature decrease in pressure in the divers' compartment as the submarine surfaced. By opening the main gas supply the divers were able to maintain pressure greater than their first decompression stop while the pilot re-submerged and the fault was rectified.

Team 2 had the experience of having an under-ballasted submarine surface as they were locking out at a depth of $18 \mathrm{~m}$. Both divers held onto the sub as it ascended and 
re-entered once the pilot had control. No attempt was made to re-enter while the sub was rising in case the sudden addition of weight caused re-submergence with possible flooding of the divers' compartment or pinning divers underneath.

Thereafter all ballast and trim tanks were completely flooded before pressurization began, and divers left the submarine at the end of the test.

All personnel were trained in submarine launch and recovery routines and most filled the surface swimmer role of hooking up and releasing lifting cables and steading lines at least once. All were trained in decompression chamber operation and were assigned tasks in rotation under the direction of the professional crew.

\section{Diving routine}

Divers dressed either in the diving locker aboard "State Wave" or in the DDC and entered the submarine fully dressed except for fins, masks, gloves, and weights, which were stored in the divers' compartment of the submarine.

Following launch, the submarine maneuvered to the dive site while divers put on fins, weights, emergency gas supply bottles, etc. When the dive site had been selected and the submarine was firmly on the bottom, the intercompartmental hatch was closed and dogged, and the lower hatch (" $A$ " hatch) undogged. Ballast and trim tanks were flooded and divers put on gloves, masks, fitted umbilicals and prepared for exit. When all was ready, blow down (pressurization) was commenced by the diver in the forward seat who regulated gas flow to give a pressurization rate of ca. $30 \mathrm{~m} /$ minute. Unisuit inflation was from bottles of compressed air carried in the divers' compartment. Once internal pressure equalled outside water pressure " $A$ " hatch fell open. The forward diver stepped into the trunk and onto the ocean bed approximately $1 \mathrm{~m}$ below the gaswater interface in the trunk. Attempting to lift the submarine gave a check that the submersible was firmly on the bottom. The forward diver then exited, carrying his hose bundle and tested that the submersible was properly ballasted. When both divers were satisfied, they began their work routine and continued until finished or their bottom time had expired. In areas of very low visibility, such as on flocculent mud, only one diver was out at a time. The after diver re-entered first (thus allowing the dive supervisor in the forward compartment clear view of both divers as they negotiated the entrance trunk), coiled and stowed the hose bundles and assisted the forward diver to re-enter. When both divers were inside, both $A$ and $B$ hatches were closed and the divers' compartment pressurized an additional $1 \mathrm{~m}$ to effect and check on a good seal. Thereafter ballast and trim tanks were blown and the submarine surfaced. Rate of depressurization of the divers' compartment and decompression stops were controlled by the dive supervisor in the forward compartment. He also advised the surface crew what pressure to have the DDC to effect transfer.

When the submarine had been retrieved and was secured on deck, the outer hatch to the divers' compartment was opened, the DDC was winched aft and the transfer tunnel bolted to the submarine. When the transfer tunnel was pressurized the inner hatch to the divers' compartment was opened and the divers dropped through the open hatch and entered the chamber where decompression was completed. 
Diving in a saturation mode differed only in that divers lived in the DDC between dives at a depth equivalent to $46 \mathrm{~m}$ breathing a $6 \% \mathrm{O}_{2}, 94 \% \mathrm{H}_{\mathrm{e}}$ mixture, and transfers to and from the submarine were made at that pressure. Other than that, routines were comparable.

\section{Scientific program}

Divers' tasks consisted of locking out at predetermined stations at $7.6 \mathrm{~m}$ depth intervals between $30 \mathrm{~m}$ and $76.2 \mathrm{~m}$. Once in the water, they were to take photographs and qualitative samples of the substrate and all common benthic species. They were to collect the epifauna from $929 \mathrm{~cm}^{2}\left(1 \mathrm{ft}^{2}\right)$ areas selected at random and collect these in numbered containers, and take in situ records of environmental parameters (temperature, $\mathrm{pH}, \mathrm{O}_{2}$ concentration and salinity) measured on a specially designed unit with remote sensors, mounted on the submarine. If any time remained, a search was made for lobsters.

All specimens collected were taken by the Environmental Protection Agency for analysis. The principal aim was the establishment of baselines for the occurrence of heavy metals, pesticides and industrial contaminants. Quantitative samples were for calibration of samples taken remotely by grabs from surface vessels.

Sampling by hand was easily accomplished by all divers, and many unusual, interesting and potentially valuable photographs were taken and observations made. For example, there is now some evidence that shrimp, Pandalus borealis, burrow in soft mud. A number were seen in shallow depressions in the mud surface in depths greater than $60 \mathrm{~m}$. One small shrimp appeared to emerge from the mud about $8 \mathrm{~cm}$ from a core tube that was being inserted, and a large one was dug out of the mud by hand while a burrow was being investigated.

A number of dry mode dives, with observers rather than swimmers in the after compartment, were made principally in a search for shrimp by personnel of the Maine Department of Sea and Shore Fisheries, but also by Boothbay Harbor personnel searching for lobster burrows in mud areas.

Teams 1 and 2 made a total of 5 training dives on air to depths of 70 feet $(21 \mathrm{~m})$ and 11 working dives on air or $\mathrm{H}_{\mathrm{e}} \mathrm{O}_{2}$ to depths of $87.5 \mathrm{~m}$. Team 3 made 2 training dives on air to 70 feet $(21 \mathrm{~m})$. Two other lock-out dives were made by the Boothbay Harbor staff accompanied by MUS\&T and National Geographic Society divers. Two dives were aborted before lock-out due to problems on the surface support boat or aboard "State Wave". These were: fouling of a support boat anchor and failure of a main winch bearing. Dives were made on all substrates ranging from mud, gravel, boulders to hard bedrock.

\section{Saturation diving problems and the "bounce" diving solution}

The original proposal was that after completing training, two teams would spend approximately 5 days each at $46 \mathrm{~m}$ depth equivalent, from which they would make 
diving excursions as deep as $76 \mathrm{~m}$ and remain there up to one hour without requiring decompression stops when returning to storage depth. This schedule was not maintained partly due to problems in handling the submarine in rough water, and delays due to equipment failure. The principal reason for lack of success in saturation diving was failure to fully anticipate and prepare for the rapid heat loss that divers experienced in the helium atmosphere of the submarine. Conditions in the DDC were comfortable at $27-28^{\circ} \mathrm{C}$. During dressing, divers would perspire heavily and undergarments frequently became saturated. The divers' compartment of the submarine was unheated and divers began to chill as soon as the submarine was launched. Selection of a dive site frequently took 30 minutes (sometimes more) by which time divers were thoroughly chilled. Heat loss was further accelerated once the divers were in the water, which was about $3.5^{\circ} \mathrm{C}$, breathing $85 \% \mathrm{He}, 15 \% \mathrm{O}_{2}$ mixture and the longest time spent out was 18 minutes. Subsequently, there were problems in retrieving the submarine due to rising seas and delay in transfer due to misalignment of submarine and transfer tunnel. Divers became dangerously chilled and were unable to meet the required work load. Thus the saturation experiment ran for 2 days instead of 5 , only one dive was made per day instead of 2 , and decompression still took 42 hours. The DDC was fully manned, 24 hours a day for the better part of 4 days for a total bottom time of less than 2 man hours. This was unacceptably costly.

The problem clearly lay in the failure to anticipate and prepare for the heat loss sustained by divers breathing $\mathrm{H}_{\mathrm{e}} \mathrm{O}_{2}$ in $3.5^{\circ}$ water. It had been assumed that Unisuits and thermal underwear would be adequate. It is now clear that auxiliary suit heating, either by hot water suits or electrically heated underwear is mandatory and should probably be augmented by heating the divers' breathing gas.

In the absence of auxiliary suit heating, the original plan for both teams to make saturation dives was abandoned and a program of "bounce" diving adopted. This would allow divers to dress on deck and remain in a one atmosphere, air environment until the submarine was sitting hard on the bottom and the blowdown commenced. There would be no helium in the suit insulation and the divers would maintain thermal stability right until the time they entered the water. The dive would then be nearing completion before the divers began to feel cold.

This system worked perfectly. The constraint now was in balancing diving time against decompression, especially at depths exceeding $60 \mathrm{~m}$, so that two dives could be made per day. With careful planning and task assignment, it was found that the work schedule could be accomplished within 30 minutes, ascent could begin within 40 minutes of blow down. Total decompression time never exceeded $33 / 4$ hours. Thus two deep dives, one by each team, could be completed in a day. Working days were still long, but there was no need for 24 -hour chamber watches. The divers were comfortable throughout the period they were in the submarine, and total bottom time and work effectiveness were at least doubled. Adoption of this system allowed much of the scientific program to be completed. Even though some scheduled dive sites were not occupied due to the limitations of the submarine handling system, dives were made in comparable depths in other, sheltered locations where the sea was not so rough. 


\section{CONCLUSIONS}

A number of minor delays and frustrations were due to problems with the submarine or its handling system. For example, significant leakage in 9 of the submarine view ports (attributed to the change from Florida to Maine temperatures) caused the loss of 2 days diving while ports were reseated and tested. Similarly, the failure of a winch bearing caused a loss of 2 working days. Some minor discomforts such as the absence of an effective shelter for the DDC were the result of a Florida based company not being aware of the climate of the Gulf of Maine in spring, and others stemmed from the use of hitherto untried systems. None affected the safety of the divers.

The principal factors responsible for failure of the program to meet all its stated objectives were: (1) The inadequacy of the submarine handling systems in moderate seas. 'This resulted in several stations not being occupied as planned, and on occasion. caused prolonged periods of discomfort to submarine crew. (2) The failure to anticipate and prepare for massive heat loss by saturated divers breathing $\mathrm{H}_{\mathrm{e}} \mathrm{O}_{2}$ caused abandonment of the saturation diving program and its substitution by the "bounce" dive program. This represents a setback to the long-range plans for saturation diving but has achieved an accomplishment in that the techniques of "bounce" diving, via lockout submarines, for research purposes to depths approaching $100 \mathrm{~m}$ are now explored and proved valid.

There is no doubt that many questions of significance in fisheries can only be answered by direct observation on the sea floor. Some of these in deeper water can therefore only be answered by the adoption of deep-diving techniques of the type described herein, where divers are able to perform tasks which could not be accomplished by remote methods from inside the submarine. They include the examination of deep-sea spawning beds. Studies of offshore lobsters and deep-water crab populations, trap loss and "ghost" fishing by lost but undamaged traps in offshore lobster and crab fisheries, the effect of trawling on bottom ecology, and others. The opportunities in pure science are infinitely wider and include questions in many branches of marine zoology, geology, and oceanography limited only by the imagination of the investigators concerned and their financial resources.

The program demonstrated convincingly that, given adequate equipment, diver scientists can be trained effectively in deep diving techniques and thereafter use these skills in fisheries or biologically oriented research.

\section{SUMMARY}

1. Six scientists and technicians were trained in lock-out diving from the submersible "Deep Diver".

2. A planned program of saturation diving on predetermined sites in depths between 150 and 250 feet $(46$ and $76 \mathrm{~m}$ ) was only partially successful because of extreme cold experienced by divers breathing heliox mixtures in $3.5^{\circ} \mathrm{C}$ water, and because of inadequacies in the submarine handling system. 
3. An alternate system of bounce lock-out dives permitted completion of an abbreviated scientific program in depths down to $287 \mathrm{ft}(87.5 \mathrm{~m})$.

4. Divers took photographs, rock and sediment core samples, and made collections of common benthic species for subsequent analysis for environmental contaminants.

5. It was effectively proved that diver scientists can train rapidly for lock-out diving programs and perform effective scientific work.

First author's address: Dr. R. A. Cooper

National Marine Fisheries Service

Boothbay Harbor, Maine 04575

USA 